\section{La Révolution française}

Cahiers de l'Institut d'histoire de la Révolution française

$11 \mid 2016$

L'Irlande et la France à l'époque de la République atlantique

\title{
Rhétorique de la souveraineté nationale irlandaise : Theobald Wolfe Tone et la République française, 1796-1798
}

\section{Sylvie Kleinman}

\section{OpenEdition}

\section{Journals}

Édition électronique

URL : http://journals.openedition.org/lrf/1656

DOI : $10.4000 /$ Irf. 1656

ISSN : 2105-2557

\section{Éditeur}

IHMC - Institut d'histoire moderne et contemporaine (UMR 8066)

Édition imprimée

Date de publication : 1 décembre 2016

Référence électronique

Sylvie Kleinman, « Rhétorique de la souveraineté nationale irlandaise : Theobald Wolfe Tone et la République française, 1796-1798 », La Révolution française [En ligne], 11 | 2016, mis en ligne le 01 décembre 2016, consulté le 21 avril 2019. URL : http://journals.openedition.org//rf/1656 ; DOI : $10.4000 /$ Irf.1656

Ce document a été généré automatiquement le 21 avril 2019.

(c) La Révolution française 


\title{
Rhétorique de la souveraineté nationale irlandaise : Theobald Wolfe Tone et la République française, 1796-1798
}

\author{
Sylvie Kleinman
}

\section{Introduction : la souveraineté irlandaise, du « fantasme » mémoriel à l'histoire}

1 Le 24 avril 1916, un détachement de nationalistes occupe la Grande Poste de Dublin lors de l'Insurrection irlandaise de Pâques et hissent deux drapeaux: le premier est le tricolore vert et orange ${ }^{1}$ qui deviendra celui de l'État libre d'Irlande en 1922 ; le second est un drapeau de fortune improvisé hâtivement par un peintre-décorateur quelques jours avant l'insurrection. Ce second drapeau véhicule le message des insurgés de manière plus claire et directe, en deux mots dorés sur fond vert et en anglais : «Irish Republic ». Jamais reconnu officiellement, alors même que le drapeau vert à la harpe a été omniprésent dans la culture nationaliste, il n'en demeure pas moins une source d'inspiration dans la mémoire collective ainsi qu'en atteste son exposition au public et sa commercialisation généralisée lors du centenaire en mars 2016, ce qui a permis de redécouvrir l'identité depuis oubliée de l'artisan, un dénommé Théobald Wolfe Tone Fitzgerald, dont les parents étaient visiblement de fins patriotes ${ }^{2}$.

2 Cent vingt ans auparavant, le 23 juin 1796, Théobald Wolfe Tone, révolutionnaire irlandais exilé à Paris depuis février, peaufine avec le général Henri Clarke les détails logistiques d'un débarquement français en Irlande sur lequel le Directoire vient de décréter. Clarke, chef du cabinet historique, topographique et militaire du Directoire (et futur duc de Feltre), fils d'un officier irlandais exilé ayant servi sous Louis XV, sert de médiateur entre Tone et Carnot, pour qui l'Irlande est devenu un véritable horizon de stratégie militaire dans la guerre contre l'Angleterre ${ }^{3}$. Le débarquement royaliste à 
Quiberon (juin 1795) avait ravivé l'anglophobie française, et une expédition irlandaise permettrait de concilier le désir de vengeance en humiliant l'ennemi sur son propre sol tout en encadrant une révolution irlandaise. Tone partage avec Clarke l'idée de former un corps d'avant garde et d'éclaireurs anglophones composé en partie de prisonniers de guerre irlandais, libérés à cet effet, qui informerait les habitants de l'île des intentions des troupes françaises débarquées. Car depuis 1793 environ, la France commence à distinguer les Irlandais des autres sujets britanniques, Anglais, Gallois ou Écossais. Ce corps franc serait spécifiquement « un corps irlandais, en habits verts, avec des plumes vertes, et un étendard vert avec la Harpe, surmontée d'un bonnet de liberté4. » L'idée de ce symbole iconoclaste mais légitimant en quelque sorte cette force armée nationale, saisit l'imagination de Clarke qui prend note de la description, en français. Il savait bien que la harpe irlandaise, ou surmontée d'une couronne anglaise ou sur fond bleu azur, était le symbole officiel de l'Irlande depuis son élévation au statut de royaume "sœur » sous les Tudors. Mais Tone lui avait sans doute expliqué la réappropriation de la harpe en tant que symbole des Irlandais Unis, dont il a été un des membres fondateurs. Ce club politique, formé en 1791, n'avait ouvertement œuvré qu'à une simple réforme parlementaire et à l'effacement des distinctions religieuses en faveur d'une véritable identité commune irlandaise ${ }^{5}$. Mais, suite à leur interdiction par les autorités en 1794, certains Irlandais Unis s'étaient regroupés clandestinement pour mener à bien leur projet d'indépendance dans le contexte propice de la guerre franco-britannique. Dès leur formation, leur sigle avait été une harpe sans couronne, accompagnée du slogan " elle a de nouvelles cordes ", soit un peuple régénéré et mûr pour la citoyenneté. Dès lors, en 1796, pour Tone et les Irlandais Unis devenus révolutionnaires, cette harpe libérée du poids de la couronne anglaise était devenue un symbole martial de ralliement. Une note du Directoire à Hoche du même jour explique qu'il était important de ne rien négliger qui pourrait contribuer au succès de l'expédition : «Les Irlandais, comme tous les peuples du monde ont une espèce de respect religieux pour certains signes et principalement ceux qui conduisaient leurs ancêtres dans les combats. » Il serait donc opportun de faire fabriquer quelques étendards, avec au centre une harpe dorée aux cordes d'argent, surmontée d'un bonnet de la liberté et sur un support de « deux branches de trèffle ${ }^{6}$."

3 Lors de la courte occupation française du comté de Mayo en août-septembre 1798, à laquelle participa Mathew, frère cadet de Tone, les Français hissent effectivement un drapeau vert comme celui décrit par Tone à Clarke. Des protestants loyalistes, pourtant conscients des injustices provoquant le mécontentement du petit peuple, sont choqués devant cette audace et témoignent avoir vu un drapeau vert avec une harpe sans couronne, et la devise en gaélique Erin Go Bragh : « l'Irlande pour toujours ${ }^{7}$ ». Les autorités du Château de Dublin lancent l'ordre de faire saisir ces preuves visuelles de haute trahison ${ }^{8}$. Suite à la défaite française lors de la bataille navale du 12 octobre 1798 au large des côtes nord-ouest de l'Irlande, un de ces drapeaux des « rebelles » est saisi à bord du navire français le Hoche. Peu de temps après, la présence de Tone en uniforme d'officier français à bord du navire est révélée ainsi que son arrestation et son emprisonnement à Dublin. Condamné à mort pour haute trahison, il ne récuse pas cette accusation mais exige la mort honorable d'un officier par peloton d'exécution. Les autorités lui refusent et, pour éviter cette infamie pour lui-même et pour l'uniforme qu'il porte, il se tranche la gorge et expire dans sa cellule le 19 novembre 1798.

4 Ces trois épisodes anecdotiques sont l'expression d'un triomphe symbolique à plusieurs niveaux, non seulement par l'identité de cet artisan militant, enfant d'une génération 
baignée de l'hagiographie des martyrs de 1798 morts pour l'Irlande et dont la mission reste à achever, mais aussi par le fait que ce drapeau de la "Irish Republic » est actuellement exposé dans l'ancienne caserne royale où Tone fut emprisonné (rebaptisée depuis Collins Barracks), aujourd'hui annexe du Musée national d'Irlande. Ils montrent également à quel point la première affirmation de la souveraineté irlandaise s'est accompagnée d'une symbolique qui a durablement marqué et imprégné les mémoires. Ils indiquent, enfin, que cette affirmation a, dès l'origine, été associée au républicanisme français en armes, à travers l'image de Tone, père fondateur du nationalisme et du républicanisme irlandais, en uniforme français. Ils posent ainsi un défi à l'historien qui souhaite faire l'histoire de ce premier républicanisme: celui-ci doit tout d'abord examiner les différents écrans mémoriels voire historiographiques, qui brouillent sa vision de la décennie 1790, nourrissant les fantasmes tout au long des deux siècles qui ont suivi ${ }^{9}$. Premier martyr de la liberté irlandaise ici reliée à un nationalisme synonyme de souveraineté nationale et populaire telle qu'elle se donne à voir dans cet usage des symboles d'une nation qui cherche à s'affirmer, mort dans des circonstances dramatiques en novembre 1798, ajoutées à la publication en 1826 de ses volumineux écrits ${ }^{10}$ - tous ces éléments font de Tone un des premiers martyrs de la liberté de l'Irlande, et sa mémoire fera ainsi l'objet d'un culte tout au long du dix-neuvième siècle, notamment au moment du centenaire de la « Rébellion » en 1898, lorsqu'il est « panthéonisé ».

Pourtant, cette réification mémorielle de 1796-1798 en 1916 passe totalement inaperçue car le centenaire de 1916 s'est focalisé assez étroitement sur le contexte immédiat, celui de la Grande Guerre et l'histoire événementielle. La transition du roman national à l'histoire savante et le phénomène des puissants lieux de mémoire comme celui de "Wolfe ${ }^{11}$ » Tone, sans parler des origines dix-huitiémistes du nationalisme irlandais ne figurent que très peu dans le calendrier des évènements. De plus, la France, et le souvenir de cette première alliance fraternelle et républicaine, n'ont eu que peu de place dans le centenaire, car, en 1916, la France, alliée à l'Angleterre dans le cadre de l'Entente cordiale, ne pouvait soutenir des « rebelles » qui cherchèrent l'appui de l'Allemagne.

6 Pourtant, le désir de venger la mort de ces premiers martyrs de la liberté et celui de suivre l'exemple des héros de 1798 sont des moteurs constants pour les insurgés de 1916, car cette première affirmation de la souveraineté irlandaise sous la bannière de la république a durablement marqué et imprégné les mémoires. Qui plus est, la rhétorique exaltée émanant du centenaire de 1898 consacre 1798 comme «l'année des Français ${ }^{12}$ ", car les expéditions militaires françaises constituaient bien une guerre de libération puisque la France avait préalablement reconnu le statut de nation au peuple irlandais ${ }^{13}$. Si dans la période précédant la Grande Guerre certains nationalistes modérés, tout en étant anglophobes et antimonarchistes, ne revendiquent initialement que le droit à l'autonomie législative et parlementaire, leurs camarades militants conspirent eux dans le but d'établir un Etat irlandais indépendant avec un seul choix possible de régime politique: la république. Dans l'imaginaire des nationalistes de 1916, Tone est emblématique de cette " première république » lointaine et mythique, qu'il s'agit de faire enfin advenir. Patrick Pearse, propagandiste et figure majeure de l'insurrection de 1916, l'éleva au rang d'un saint républicain dans un discours clef sur sa tombe en 1913, rite charnière qui représente en lui-même un des plus puissants lieux de mémoire irlandais :

C'est à son enseignement que nous devons l'existence d'une si grande chose que le nationalisme irlandais, et c'est à la mémoire des exploits de sa génération à qui il avait redonné leur vigueur, à la mémoire de 1798, que nous devons qu'il reste la moindre virilité en Irlande ${ }^{14}$. 
7 L'exemple de Tone fut une motivation déterminante pour les insurgés de 1916, mais son image et sa personne furent aussi gravement ternies par les paramilitaires des décennies suivantes. Ceux-ci s'approprièrent son énonciation de la souveraineté irlandaise, en l'arrachant de son contexte dix-huitiémiste pour en faire une arme idéologique dans leur combat meurtrier contre la présence britannique en Irlande du Nord. En parallèle, Tone est aussi le plus connu et le plus chéri des héros irlandais, en partie car c'est aussi le plus loquace: la lecture de ses écrits, et surtout de son volumineux journal qui est franc, engageant et minutieusement observateur des faits et des émotions marquant sa trajectoire, constitua une activité patriotique commune et formatrice. Si l'Irlande est bien un pays où " l'histoire est autobiographique, et l'autobiographie historique ${ }^{15}$ ", il fut le pionnier du genre, mêlant intimement son destin personnel à celui de son pays. Il fut adulé (à tort) comme le fondateur des Irlandais Unis et le dirigeant de la rébellion de 1798 , et (à raison) comme celui qui le premier exprima avec clarté la revendication irlandaise de la souveraineté irlandaise. La maturation de la science historique en Irlande et l'influence positive du bicentenaire de la Révolution française ont donné lieu à un défi savant pour corriger cette distorsion du personnage. La principale biographie de Tone, œuvre exceptionnelle de Marianne Elliott, a permis de reconstruire sa vie dans un contexte purement historique et a examiné ses motivations en s'appuyant sur des archives en partie inédites ${ }^{16}$. Finalement, la publication de ses œuvres complètes annotées a permis de mettre à disposition une ressource précieuse pour approfondir l'étude de son parcours. Réhabilité dans cette phase post-apothéose, notamment depuis l'accord de paix en Irlande du Nord de 1998, qui coïncida avec le bicentenaire de la «Rébellion » de 1798, Tone a été pourtant particulièrement absent des commémorations et des débats autour du centenaire de l'Insurrection de 1916. Or, Theobald Wolfe Tone est l'incarnation même de cette histoire commune franco-irlandaise ancrée dans un mythe partagé du geste martial, mais aussi de la diffusion de la Révolution française au-delà de ses frontières, car il est avant tout un agitateur politique puis un révolutionnaire, le premier à formuler la vision d'une Irlande souveraine et d'une nation reconnue à l'échelle internationale. Cette vision de l'Irlande est ancrée dans les principes démocratiques du républicanisme, dont il fera l'apprentissage en France de 1796 à 1798, aussi bien dans la sphère civile que militaire ${ }^{17}$. Il est donc opportun de revoir comment le républicanisme français et sa culture politique, de 1796 à 1798, formèrent un cadre si fertile pour cette phase décisive de sa trajectoire au cours de laquelle il affirme par divers moyens le droit de l'Irlande à se proclamer une nation.

\section{Le journal de Tone, un témoignage intime de la cristallisation de son républicanisme}

8 L'intention de Tone n'a jamais été que son journal devienne un traité théorique. Ce n'est pas un penseur politique systématique comme le souligne son biographe, et il n'y cite ni Montesquieu ni Rousseau ${ }^{18}$. À cette riche source il faut associer la correspondance, mais aussi une courte autobiographie rédigée après l'obtention de son brevet d'officier français dans les semaines avant le départ de l'expédition de Hoche en décembre 1796. Le fait même qu'il ait rédigé ce mémoire autobiographique est un indice que Tone était conscient d'être un acteur de l'histoire, mais dans un chapitre qui pourrait fort bien le mener vers la mort. Tout écrit confessionnel est subjectif, et donc pour l'historien une source à manier avec précaution. Mais il y exprime, en privé, ses motivations et celles de 
ses associés politiques, difficiles sinon impossibles à exprimer publiquement et ouvertement avant son exil d'Irlande en 1795. Ce mémoire constitue donc une source extrêmement précieuse. Au cours de la première phase cruciale de sa mission à Paris, on y retrouve son regard aiguisé sur la teneur des innombrables séances de négociations qui mèneront à la décision du Directoire, en juin 1796, de décréter le déploiement d'une expédition militaire en Irlande ${ }^{19}$. Plusieurs communications internes entre les décideurs politiques et militaires français permettent, en parallèle à cette source subjective, de suivre sa présence dans les couloirs et salons et ses entretiens avec Clarke, Carnot et Delacroix. Il est frappant de constater qu'au cours de ces échanges, lors de cette première phase de l'alliance franco-irlandaise, l'établissement spécifique d'une république comme objectif politique de l'intervention militaire n'allait pas de soi. Certains officiels français avaient conservé un préjugé, remontant à l'Ancien Régime, selon lequel la préférence du peuple irlandais, ou de son aristocratie catholique, irait à une monarchie. Pour Tone, cependant, le système républicain, même s'il n'était pas toujours explicitement désigné, était la seule forme de gouvernement envisageable pour une Irlande souveraine, car le seul qui soit fondamentalement démocratique et représentatif d'une citoyenneté unie. C'est ce double paradoxe, cette double absence, qu'il s'agit ici de comprendre.

Contraint de s'exiler pour son implication avec l'agent secret franco-irlandais William Jackson en 1794, Tone s'installe aux États-Unis avec sa famille. Mais les archives démontrent que, moins d'une huitaine de jours après son arrivée à Philadelphie, il se présente le 10 août 1795 à Pierre-Auguste Adet, ministre plénipotentiaire de la République française aux États-Unis. Suite à ce premier entretien au cours duquel le diplomate français est courtois mais ne s'engage à rien, il lui demande de coucher par écrit la teneur de propos échangés verbalement le matin ${ }^{20}$. Ce mémoire révèle en quoi consista la première approche directe de Tone auprès du Directoire, mais nulle part dans cette première plaidoirie ne trouve-t-on le terme de république. Cette absence est symptomatique du flou qui caractérise plusieurs étapes clefs de sa mission ainsi que les documents de propagande qui en émanent. Il est difficile sinon impossible de l'élucider complètement: peur de heurter une opinion irlandaise en temps de guerre en lui imposant le terme de république synonyme de trahison? Résultat de la hâte dans laquelle ces documents étaient rédigés? Ces hypothèses ne sont pas totalement satisfaisantes lorsqu'il s'agit d'évoquer l'œuvre d'un très habile propagandiste et d'un révolutionnaire devenu hors-la-loi et exilé de son pays.

Ceci dit, l'indépendance irlandaise, en tant que but politique de ce recours indispensable à l'insurrection armée, est évoquée avec éloquence, et implicite à chaque ligne du document. Tone affirme qu'une invasion française en Irlande serait « soutenue par tous à l'exception de l'aristocratie et de ceux qui dépendent directement d'elle. [...] Les sept huitièmes de la population irlandaise rejoindraient l'armée d'invasion, une fois satisfaites des principes sur lesquels l'invasion se ferait ${ }^{21}$. " C'est une exagération considérable du pourcentage de la population prêt à s'allier, ou à collaborer, ou même s'accommoder d'une force armée française représentant une république séculière, mais Tone ne manque pas d'audace. Il insiste également dès ce premier contact sur certaines conditions que les Irlandais Unis avaient visiblement formulées avant son départ d'Irlande. Les intentions françaises devaient être clairement exprimées dans une proclamation que le général ferait circuler dès le débarquement, car certains principes devaient guider leur conduite en Irlande: «le but [des Français] serait l'affranchissement, et non la conquête de l'Irlande »; ils garantiraient "l'indépendance, les droits de conscience et la liberté des 
religions et des opinions ${ }^{22}$.» Nous retrouvons ces conditions tout au long des mois de négociations, et dans plusieurs documents du débarquement, indiquant que les Irlandais Unis n'étaient pas prêts à se soumettre à tout prix aux ambitions expansionnistes de la France. Tone termine en insistant que la « séparation de l'Angleterre et une alliance avec la France est le désir le plus sincère de la grande majorité du peuple irlandais, et ce serait à la gloire de la République [française] d'émanciper un pays qui depuis sept siècles mélancoliques gémit sous le joug de la tyrannie britannique ${ }^{23}$. »

11 Une fois arrivé à Paris en février 1796, les entretiens de Tone avec divers décideurs portent essentiellement sur la logistique et la stratégie militaire, dimensions porteuses d'importantes retombées politiques. Le débarquement d'une force française substantielle et aguerrie était une condition essentielle pour éviter une guerre civile, et faire de ce conflit une véritable guerre d'indépendance, insistait Tone. Le conflit armé serait transformé en "révolution", facilitant l'établissement immédiat d'un gouvernement « révolutionnaire ». Dans un premier mémoire rédigé en France à la demande du ministre des relations extérieures Delacroix, Tone avait décrit les composantes de la société irlandaise soulignant bien l'union récente entre les Dissenters, (presbytériens calvinistes d'origine écossaise, environ dix-sept pour cent de la population) dont les préventions viscérales contre le "papisme" avaient été en très grande partie levées suite à l'établissement récente de la liberté de conscience en France, et les catholiques (qui formaient une majorité d'environ soixante-dix pourcent), provoquant l'alarme, la terreur et la confusion du gouvernement anglais et de ses partisans, l'aristocratie anglicane d'Irlande. Il insista sur les principes sincères du républicanisme des Dissenters (qui s'autogouvernaient sans évêques), et se félicitait de cette "union cordiale ${ }^{24}$ » avec les catholiques. Ceux-ci représentaient presque toute la paysannerie, mais aussi une proportion importante des commerçants et des négociants de l'île, tous «fort respectables et bien informés » de leur situation ainsi que celle de leur pays. Delacroix, dans son premier rapport au Directoire, avait bien avoué «que le catholicisme comme point de ralliement des mécontens d'Irlande ${ }^{25}$ " n'était guère rassurant pour un gouvernement républicain, et Tone avait dû rassurer ses interlocuteurs sur ce sujet. L'union entre Dissenters et catholiques n'était rien de moins qu'une « révolution dans la moralité politique de la nation ", dont découlerait l'indépendance, la liberté, et la mise en œuvre d'une république libre. Synthétisant la complexité socio-ethnique de la situation politique pour les décideurs français, Tone avait ainsi dépeint indirectement sa vision utopique d'une Irlande libérée des distinctions artificielles. Un deuxième mémoire se penche davantage sur les mesures logistiques à court et à moyen termes et la stratégie militaire, mais aussi quelques mesures intérimaires que pourraient prendre un gouvernement provisoire. Tout dépendrait d'un manifeste, à diffuser dès le débarquement, dans lequel on inviterait le peuple à se rallier à l'étendard « républicain ${ }^{26}$ »- nous présumons qu'il veut dire celui de la France, mais également, par association, celui de l'Irlande combattant pour son indépendance - qui encadrerait les opérations dans un premier temps. Puis on inviterait le peuple à "former une convention nationale » dans le but de former un gouvernement provisoire. Certes, le modèle de la guerre d'indépendance américaine soutenue par l'intervention militaire française est perceptible, mais cette première tentative de révolution irlandaise serait marquée par l'idéologie commune des Irlandais Unis et du Directoire.

12 Après son premier entretien avec Clarke, Tone n'avait pu s'empêcher de déconstruire dans son journal ses idées erronées sur l'Irlande, démontrant que ce conseiller auprès du 
Directoire était particulièrement mal informé sur l'Irlande, notamment sur ses transformations sociales récentes. Le point le plus irritant sur lequel Clarke insistait était que l'aristocratie irlandaise ait pu accueillir favorablement une expédition française, et que certains de ses membres pourraient éventuellement «concourir à la tentative d'établir l'indépendance de leur pays. » Pour Tone, qui ne cacha jamais son dédain envers la noblesse et de ses privilèges héréditaires, Clarke avait fondamentalement tort. Certes, il n'était pas impossible que le Duc de Leinster ${ }^{27}$ se rallie au peuple « une fois la révolution entamée », parce qu'il le considérait comme « a good Irishman ${ }^{28}$ ", un bon Irlandais, reflet de la conception de Tone selon laquelle le dévouement à la cause ultime de la nation et le droit de se dénommer Irlandais étaient inséparables. Mais à ses yeux, l'engagement de tel ou tel individu n'aurait plus d'importance après « le début ». Cela montre que, pour lui, la révolution est un mouvement, un élan. Toutefois, les idées reçues de Clarke étaient tenaces et refirent surface le jour enfin venu où il honora Tone ("James Smith ») en lui livrant son brevet de chef de brigade. Suite à une embrassade fraternelle et toute républicaine et un salut règlementaire, il fallait reprendre quelques points délicats : les Irlandais seraient-ils, demanda Clarke, consentants si la France se voyait obligée de s'ingérer dans leurs affaires, ce qui serait peut-être nécessaire dans un premier temps, comme à l'heure actuelle en Hollande. La France, continua Clarke, n'avait " aucune garantie quant à la forme de gouvernement que les Irlandais comptaient adopter, en cas de succès. » Ici, l'opinion de Clarke ne semble pas spécifique à l'Irlande. En effet, Clarke, lorsqu'il est envoyé en Italie peu après (décembre 1796) auprès de Bonaparte, transmet un rapport dans lequel il souligne que les Italiens ne sont pas mûrs pour le gouvernement républicain et prônant à Delacroix l'idée de s'adjoindre le concours du clergé italien pour mieux guider le peuple jugé superstitieux ${ }^{29}$. Il est dès lors possible de supposer que les réserves initiales de Clarke et du Directoire étaient moins spécifiques à l'Irlande qu'elles n'exprimaient une perception de l'« exception » française et de la stratégie à adopter, d'ailleurs sources de nombreuses divisions au sein du Directoire, d'autant plus que ce dernier était littéralement assailli de demandes de patriotes bataves, italiens, suisses et, donc, irlandais pour intervenir dans leur pays respectif ${ }^{30}$.

L'opinion décidée de Tone était "qu'on établirait une république », ce à quoi Clarke répliqua qu'ils établiraient peut-être une république aristocratique comme celle de Gênes. Tone, inflexible, rétorqua que les aristocrates d'Irlande étaient loin d'avoir les faveurs du peuple, et qu'on ne verserait jamais «notre sang pour établir leur pouvoir ${ }^{31}$. " Tone est loin d'être un sans-culotte, mais il semble anticiper positivement les privations à venir. Il rassure Clarke que « nos alliés [français] » ne manqueraient de rien sur place et seraient approvisionnés, par réquisition si nécessaire. À Clarke qui s'inquiéta alors de ce que pourrait être la réaction des grands propriétaires terriens, Tone répondit qu'on «ne faisait pas la révolution pour les propriétaires terriens ", leurs amis parmi les privilégiés seraient prêts à faire des sacrifices, et leurs ennemis en souffriraient les conséquences. L'exemple de la révolution en France en était une démonstration, et " pendant la lutte pour leur liberté il avait été scandaleux pour les Américains de jouir du luxe et des commodités de la vie tant et si bien que même les plus grands propriétaires terriens et les personnes au statut le plus élevé avaient porté des vieux vêtements rapiécés ${ }^{32}$.» Il espérait toutefois que la révolution serait accomplie avant que l'enthousiasme initial ne s'affaiblisse.

14 Le franc-parler de Tone est ici frappant et contraste avec son omission du mot « république » dans les premiers mémoires. Il n'est ainsi guère étonnant que la lecture 
sélective de son journal ait permis à d'innombrables auteurs d'en tirer des citations qu'ils estiment représentatives de sa pensée politique, pour ensuite lui coller des étiquettes et nourrir les querelles historiographiques. Ceci dit, une lecture prudente peut porter ses fruits car les écrits de Tone demeurent un terrain fertile pour étudier les mentalités de cette époque charnière dans laquelle émerge « une nouvelle dimension de la guerre vis-àvis de la république ${ }^{33}$. » C'est, par exemple, dans le cadre de discussions sur les effectifs déployés que Tone regrette qu'avec une force limitée à 5000 hommes, on ne pourrait avancer que sur la base "d'un plan révolutionnaire", ne compter "que sur les sansculottes $^{34}$ » et tout réquisitionner. Si les propriétaires terriens ne nous soutiennent pas, déclare-t-il, «ils doivent tomber, et nous pouvons nous soutenir nous mêmes avec l'aide de cette classe nombreuse et respectable de la communauté, les hommes sans propriétéé ${ }^{35}$.» Cette expression deviendra une phrase clef dans l'historiographie des Irlandais Unis, et suffira pour qu'on déclare "Tone comme Jacobin ${ }^{36}$.» C'est certes une déclaration qui semble catégorique, mais puisée dans une source rédigée dans le vif de l'émotion, le journal, et à peine trois semaines après son arrivée à Paris. En remontant quelques lignes plus haut, Tone relate la discussion du jour avec Delacroix, et lui avait dit que l'assistance des propriétaires leur serait essentielle pour former un gouvernement rapidement. Deux mois plus tard, il s'avoue fort satisfait de l'action décisive du gouvernement contre les babouvistes et se définit lui-même comme n'étant "pas aussi ultra-révolutionnaire que certains [de ses interlocuteurs à Paris] ${ }^{37}$. " En février 1798, il relate avec enthousiasme la vive réaction de Bonaparte contre la montée pré-électorale des néojacobins, qu'il admire : " nous ne reconnaissons comme chefs et leaders que ceux qu'indiquent la constitution, le corps Législatif et le Directoire Exécutif ${ }^{38}$.» En fait, pour lui, seul un gouvernement français fort et uni peut faire avancer le projet des expéditions en Irlande et la souveraineté de son pays, objectif qu'il veut atteindre à tout prix et sur lequel il reste complètement focalisé.

En réalité, ces contradictions apparentes, assez naturelles dans un journal personnel, ne doivent pas faire oublier que Tone montrait ici son pragmatisme grandissant et cherchait à éviter de trop se compromettre dans la politique française pour ne pas mettre en péril sa mission en faveur de l'Irlande. Ce pragmatisme se retrouve dans sa constante préoccupation d'éviter les milieux immigrés à Paris, y compris et surtout irlandais, avant de rester, selon sa propre expression, un "ambassadeur incognito ${ }^{39}$.» Tone avait une vision peut-être plus réaliste sur la phase intérimaire d'occupation, reflet d'une évolution personnelle. Encore novice dans l'art de négocier une alliance militaire en mars 1796, il avait été choqué par le projet favori de Carnot: fomenter un esprit de chouannerie en Irlande dans une phase préliminaire au débarquement, en y introduisant des malfrats et forcenés qui sèmeraient la terreur et le chaos. Tone insista sans relâche pour faire admettre au gouvernement français l'idée que les Irlandais étaient suffisamment prêts à se soulever eux-mêmes, que cette mesure ne ferait qu'entraîner des insurrections sporadiques facilement écrasées par le gouvernement anglo-irlandais et dont les principales victimes seraient les plus braves et ardents des paysans, et que l'ennemi n'en sortirait que renforcé. Mais si la République déployait une vision plus large et une politique plus raisonnée, alors on pourrait embraser les quatre coins de l'Irlande pour en expulser les Anglais ${ }^{40}$. Lors de la préparation de la seconde expédition, ses réactions au coup d'état des radicaux bataves du 22 janvier 1798 éclairent sur les espoirs qu'il place dans l'aide française mais aussi sur ses inquiétudes. En tant qu'étranger privilégié qui avait lui-même séjourné en Hollande et y avait fréquenté plusieurs dignitaires, il avait pu observer de près, à l'instar d'autres agents étrangers, «les oscillations et lenteurs du 
gouvernement provisoire de Hollande ${ }^{41}$. » La coopération de la flotte batave représentait en 1797 un maillon essentiel de la stratégie navale française, et donc la clef du succès du débarquement en Irlande. Hoche avait détaché Tone auprès du général Daendels début juillet, et de retour à Paris, Tone avait même joué un rôle mineur dans les préparatifs de l'intervention française au coup d'état, ayant servi d'intermédiaire entre l'émissaire de Daendels à Paris et le général Desaix. Il cite avec engouement ce dernier dans son journal: «la formulation de Desaix a été, "puisque vous ne voulez pas vous faire une constitution on vous priera d'en accepter une, et j'espère que vous ne la refuserez pas" ${ }^{\prime 2}$. " Tone ne remettait ainsi pas en cause le comportement, qu'il jugeait justifié, des Français qui avaient laissé aux Hollandais la liberté et le temps d'organiser leur propre gouvernement et rédiger leur propre constitution. Il doutait toutefois que les Irlandais démontreraient une telle incapacité, mais si tel devait être cas, alors il approuverait une ingérence française. C'est d'ailleurs lors d'un court séjour en République batave qu'il s'engage dans une démonstration pour conclure que le gouvernement d'une république « correctement organisé et librement et fréquemment choisi par le peuple devrait être un gouvernement fort ${ }^{43}$. " Mais était-t-il devenu trop crédule, approuvait-il trop facilement «la politique étrangère plus agressive et interventionniste du second Directoire ${ }^{44}$ »? Pas tout à fait, comme en témoigne son inquiétude à propos de la manière dont il interrogea Hoche sur le comportement de Bonaparte vis-à-vis de Gênes :

Je saisis alors l'occasion pour mentionner un sujet qui pesait lourdement sur ma conscience, à savoir le degré d'influence que les Français seraient disposés à s'arroger en Irlande, et pour lequel j'avais de grandes raisons de craindre qu'il soit bien supérieur à celui que nous pourrions décider de leur octroyer. Dans la gazette du jour figurait une proclamation de Buonaparte adressée au gouvernement de Gênes, que je jugeais grossièrement malséante et indécente puisqu'elle enfreignait sur les droits indispensables du peuple. Je lus à Hoche les passages les plus indécents, et je fis observer que si Buonaparte commandait en Irlande et en venait à publier une proclamation aussi intrusive, elle aurait les conséquences les plus fâcheuses; qu'en Italie un tel diktat puisse être accepté, mais jamais en Irlande où nous n'étions que trop conscients de nos droits pour nous y soumettre.

La réponse de Hoche rassure en partie Tone: le général condamne la conduite de son rival. Mais, perspicace, il y voit de la part de Hoche de la jalousie envers Bonaparte, et se lamente que le général victorieux en Italie ait perdu « son esprit de modération », ce qui ne l'empêche pas de revenir immédiatement aux plans de la prochaine expédition ${ }^{45}$.

Ainsi, loin d'être naïf sur ce que pouvait signifier l'aide française, Tone - et avec lui des Irlandais Unis - était en même temps conscient qu'elle était indispensable pour espérer réussir une "libération" la moins sanglante possible en se ralliant les notables, ce qui permettrait, dans un second temps, d'établir une république, ainsi que ses proclamations le démontrent.

\section{Le républicanisme et l'expression de la souveraineté nationale irlandaise dans les adresses et proclamations au peuple irlandais}

18 En parallèle aux discussions verbales et à la circulation interne d'argumentaires écrits, dont l'utilité n'était qu'à court terme, un effort considérable de communication et de propagande devait accompagner les expéditions de 1796 et 1798. Plusieurs adresses et proclamations, à distribuer dès le débarquement, furent composées et traduites de 
l'anglais en français (et vice-versa), pour approbation interne du Directoire. Disponible dans les archives françaises, et reproduites dans les œuvres complètes de Tone, ce corpus de sources a pourtant été presque entièrement négligé par les historiens, leur perspective étant sans doute trop téléologiques, l'échec des expéditions ayant minimisé l'intérêt de ces documents révélateurs des intentions stratégiques et politiques franco-irlandaises. Ces derniers, de prime abord, semblent effectivement surtout porter sur la logistique et la stratégie, donc sur des préoccupations de court-terme et recélant un intérêt surtout pour l'histoire militaire. Mais, pour la courte période qui nous concerne, une rhétorique puissante de changement politique accompagne la guerre et encadre les acteurs de l'histoire, même s'il est vrai que derrière ce langage idéologique omniprésent (et souvent pesant) se cachent des motivations mercenaires et pragmatiques loin des droits des peuples. Dans le cas de Tone, en négligeant ces textes qu'il a rédigés dans le cadre sécurisant de la France et ainsi libéré de la crainte des persécutions, c'est se priver de sources directes sur la mentalité et la vision des Irlandais Unis ${ }^{46}$. C'est pourtant un truisme que de rappeler qu'il existe un déséquilibre flagrant entre le nombre relativement restreint de sources écrites ayant survécu illustrant leurs idées, et produites de manière spontanée, et le volume considérable de documents officiels reflétant le conflit du point de vue des autorités. Donc, même si les objectifs de Tone dans tous ces textes rédigés pour les expéditions sont immédiats, et n'évoquent pas, sur le plan macropolitique ni un projet de société ni les institutions démocratiques d'un Etat irlandais indépendant, il n'est pas inintéressant de se pencher sur un court échantillon.

Une Adresse au peuple d'Irlande sur l'importante crise actuelle que Tone rédige (en anglais) à Rennes et à Brest entre octobre et novembre 1796 est un document significatif, même s'il est long et son style laborieux. Anonyme, il constitue néanmoins la première occasion que l'histoire offre à Tone d'annoncer librement et ouvertement à ses compatriotes leur révolution ${ }^{47}$. Cette communication aux Irlandais, qui aurait dû être distribuée au moment du débarquement, est avant tout un outil de propagande et de persuasion pour rallier le peuple et, en annonçant le programme des mesures intérimaires qui assureraient un gouvernement provisoire, se garantir le soutien des civils importants. Tone en parle de temps en temps comme d'un manifeste, et il en est question tout au long des négociations. Une traduction est fournie au général Hoche, qui veut des garanties sur le cadre politique de ses faits d'armes. Comme nous le savons, le débarquement espéré sur le sol irlandais n'eut jamais lieu en 1796, mais les autorités françaises avaient fait imprimer l'adresse à Brest avant le déploiement de la flotte en décembre, et elle fut de nouveau utilisée pour l'expédition d'octobre 1798 qui mena à l'arrestation de Tone. Une copie de l'adresse fut saisie à bord du navire français le Hoche qui le transportait et, pour médiatiser la menace contre l'ordre et la paix des fidèles sujets de la Couronne que tentaient d'importer les Français, l'adresse fut réimprimée par les autorités. Sur la couverture du pamphlet figurait une date et un lieu d'impression fictifs (Belfast, 1796), et une brève introduction dénonçant le style déclamatoire qui exposait les mensonges insidieux de cette adresse découverte sur le Hoche; une allusion indirecte est faite aux événements récents, mais Tone n'est pas mentionné. Une fois la nouvelle de son arrestation en uniforme français diffusée dans la presse, le public pourrait tirer ses propres conclusions. Le fils de Tone en avait trouvé une copie parmi ses archives, et l'adresse fut donc réimprimée avec une tout autre intention en 1826 avec l'autobiographie de Tone (rédigée elle aussi juste avant l'expédition de 1796), puis dans les œuvres complètes en $2001^{48}$. 
Irlande avant son exil, climat répressif qui l'avait conduit à s'autocensurer et que son Irlande avant son exil, climat répressif qui l'avait conduit à s'autocensurer et que son biographe n'évoque peut-être pas assez comme facteur pour comprendre la chronologie de son républicanisme ouvertement revendiqué. "Le temps est enfin venu pour qu'un ami de la liberté et de l'indépendance de l'Irlande dise la vérité et examine la situation de son pays ${ }^{49}$ ", débute-t-il, " sans craindre [...] de se retrouver devant un juge. » Il ne fait aucune allusion directe au contexte libérant sa plume qu'est sa terre d'asile, et n'évoque que très indirectement par le mot «crise » la présence d'une force armée débarquée en Irlande, et les faits d'armes nécessaires pour révolutionner le système politique. Pour Tone, il est temps de mettre fin à la misère et à la soumission de son pays natal que déplorait depuis des siècles tout honnête Irlandais. La voix anonyme voit à l'horizon un «nouvel ordre en Europe. » La révolution inouïe en France a établi « une république formidable (a mighty republic) sur les larges et solides fondements de l'égalité des droits, des libertés et des lois. " Dans un texte qui s'étend sur seize pages dans la version imprimée, Tone évite totalement de déclarer formellement une république d'Irlande est-ce intentionnel? Nous ne le saurons jamais, et la question nous semble avoir peu d'importance, car le système républicain est explicite dans tous ses propos, notamment dans la référence à la République française. L'objet immédiat de son attention, déclare-til, n'est pas telle ou telle forme de gouvernement, mais l'indépendance. Ce mot, ainsi que « liberté », dominent l'ensemble du texte. L'Irlande n'avait qu'un choix : « entre l'union ou la séparation! [...] entre l'indépendance et l'esclavage ; il n'y a pas de troisième voie. »

Dans une courte analyse de l'Adresse, Stephen Small classe ce texte chronologiquement dans la phase «républicanisme et séparatisme» de la pensée politique irlandaise ${ }^{50}$. Pourtant, Small, s'il souligne bien que l'adresse est un outil de propagande, dans une tentative de vouloir classer à toute force la pensée de Tone dans des courants spécifiques, néglige la puissance de la rhétorique de liberté que Tone déploie, et son caractère proprement révolutionnaire inséré dans le contexte européen de 1796. Tone est en effet persuadé « que la doctrine du républicanisme finirait par subvertir celle de la monarchie pour établir un système de liberté juste et rationnelle sur les ruines des trônes des despotes de l'Europe ${ }^{51}$. " Pour Small, cette prise de position audacieuse en faveur du républicanisme n'est pas caractéristique du style de Tone et l'étonne, démontrant plutôt que sa ferveur républicaine n'avait pas complètement éteint le sentiment de supériorité protestante dont il hérite également en tant que patriote irlandais : sa vision de la liberté politique était enracinée dans la Réforme, charnière importante dans la progression de l'esclavage vers la liberté qui ne pouvait passer que par le renversement du papisme. Si cette déconstruction minutieuse est valide, elle contourne totalement la rhétorique de la France de 1796. Tone ne cherche-t-il pas après tout à persuader une large gamme d'Irlandais ? N'adopte-t-il pas un certain langage à des fins stratégiques?

Tone déclare qu'aucun bien ne pourrait découler d'une législature qui ne partagerait aucun intérêt avec le peuple. Désormais, l'admission à la législature ne sera plus achetée avec l'argent et le système exécrable de corruption sera détruit à jamais. Certes, si la paysannerie n'est mentionnée que dans son état victimaire, un concept important est introduit : ce sera le devoir d'un " gouvernement national » de répondre à leurs doléances et d'édifier leurs esprits, d'examiner leurs plaintes et d'alléger leurs souffrances. L'union contre nature entre l'Eglise anglicane et l'Etat qui avilit la religion, devenue outil politique, sera dissoute, et aucune religion n'aura le droit exclusif de gouverner les 
citoyens; aucun citoyen ne sera exclu du suffrage pour avoir vénéré Dieu selon sa conscience. Il ne sera jamais question de déchristianiser, mais de séculariser.

En un mot l'Irlande sera indépendante. Nous serons une nation et non une province, des citoyens et non des esclaves. Le rang de chaque homme dans l'Etat sera décidé en fonction de son talent et de ses mérites. Notre commerce s'étendra aux quatre coins du globe, notre drapeau flottera sur les mers, et notre nom sera connu parmi les nations du monde ${ }^{52}$. Français pour démontrer leur bravoure en défendant leur terre natale. Tone s'adresse d'abord aux braves soldats dans un style élégant et métaphorique, annonçant que le moment est enfin venu pour chaque Irlandais de libérer son pays. La République française fournit armes, munitions, des milliers de troupes et un de ses plus grands généraux, « non pas pour envahir notre pays mais pour nous permettre d'affirmer notre liberté ${ }^{54}$.» A aucun moment, ces deux adresses ne déclarent une république d'Irlande. Elles contournent également la principale difficulté en n'identifiant jamais les confessions religieuses polarisées puisque politisées : la majorité des hommes du rang de la milice irlandaise sont catholiques, et les officiers protestants, dans ce corps levé en 1793 lorsque la guerre avec la France a précipité la levée de l'interdiction des premiers à manier les armes. Tone demande ce qu'offre l'ennemi, et rappelle à ses lecteurs qu'aucun des simples soldats n'a le moindre espoir d'être élevé au rang d'officier. Il avait affirmé à plusieurs reprises aux décideurs français que la majorité des miliciens déserterait pour se ranger du côté des insurgés, et donc de leur patrie, ce qui ne sera nullement le cas en 1798. Il annonce qu'en agissant comme de braves soldats et de bons Irlandais, en refusant de servir la cause du tyran contre leur pays natal mais, inversement, en servant la cause d'une "armée nationale irlandaise ${ }^{55}$ ", la voie de la promotion leur serait ouverte : le courage et les talents seront recherchés et non le rang ou la fortune. Il cible donc les catholiques, majoritaires. L'adresse aux matelots adopte elle aussi un style franc et direct, sans fioritures lexicales et minimisant les méandres syntaxiques, donc facile à absorber surtout si l'exhortation est lue à haute voix. En dépit du niveau relativement modeste d'instruction de son public, Tone invoque néanmoins leur honneur. L'Irlande est désormais une nation indépendante, mais doit se battre contre l'Angleterre pour défendre ses libertés; la France est l'alliée de l'Irlande et l'Angleterre est l'ennemi commun des deux nations. Le devoir patriotique devient presque une formule arithmétique. Il encourage la saisie des vaisseaux et des marchandises pour les diriger vers les ports irlandais. Les symboles ne sont pas absents : « Souvenez-vous que l'Irlande est à présent une nation indépendante. Vous n'êtes plus sujets du roi d'Angleterre [...]. Qu'est-ce qui vous empêche de prendre immédiatement le contrôle des vaisseaux [...], de hisser le drapeau irlandais et de vous diriger vers les ports d'Irlande ${ }^{56}$ ? " Le langage qu'emploie Tone est généralement celui employé par les Irlandais Unis : franc, direct et concret, éloquent mais avant tout pragmatique. Par contre, étant donné la loquacité et la franchise de son journal, nous constatons aussi qu'il n'y évoque jamais une volonté délibérée d'éviter le mot " république ».

En dépit de l'échec des expéditions de 1798, cette année consacrée « année des Français » deviendra un des lieux de mémoire les plus puissants du nationalisme irlandais, et 
l'intervention de la France un "évènement fondateur ${ }^{57}$ ", en parallèle aux faits d'armes des Irlandais Unis, prêts à tout sacrifier au nom de la liberté. Il est donc naturel que la proclamation distribuée par le général Humbert par ordre du Directoire sur les rivages du comté du Mayo, dont des exemplaires sont lus avec effroi par des civils loyalistes, puis préservés dans les archives officielles, soit aussi mythifiée. Constituant un recyclage des textes précédents, que certains attribuent à Clarke lui-même, la proclamation de 1798 a au moins le mérite de tenir sur une seule page : les Français viennent « pour joindre leurs armes et mêler leur sang " à celui de leurs frères d'armes Irlandais pour " la cause sacrée de la liberté.» Les conditions de l'alliance fraternelle sont visuellement détachées du reste du texte en italiques : la France jure le respect des lois et des opinions religions, car elle ne recherche aucune autre conquête que celle de la liberté des Irlandais. Mais les dernières lignes nous intéressent particulièrement: "Union, Liberté, République irlandaise! Tel est notre $\mathrm{cri}^{58}$.» En dépit de la phraséologie pesante et alourdie par des gallicismes, bien loin de l'éloquence laconique de Tone dans l'Adresse, le nouveau régime est pourtant explicitement déclaré.

Il apparaît ainsi que si ne Tone mobilisa que peu la référence explicite à la république et davantage celles à l'indépendance et au nationalisme, cela ne signifie pas pour autant que le langage du républicanisme n'était pas sous-jacent à tout son discours, car indépendance et nation étaient synonymes de souveraineté. Et s'il s'attarde peu sur le détail des futures institutions irlandaises, c'est parce qu'il ne peut y rêver tant que la révolution ne sera pas faite, mais il est certain que seule une démocratie représentative et méritocratique - une république - peut remplacer le système en place. Ce qui importe c'est l'union des Irlandais, vision qu'il transporte vers de futures générations, et dont il a en partie puisé l'inspiration dans la culture républicaine du Directoire.

\section{L'exil parisien et l'apprentissage de l'esprit civique à travers la fête républicaine}

En parallèle à la restitution quotidienne de sa fréquentation des hautes sphères politiques au cours de ses négociations, l'héritage écrit que Tone lègue aux générations futures comporte une autre dimension essentielle du républicanisme français qui joua un rôle déterminant sur sa propre vision pour une autre Irlande. Loin d'être secondaire, elle a pourtant été contournée et sous-exploitée par les interprètes de son parcours idéologique. Tout lecteur de son journal pour les premiers mois de son exil en France fait la découverte, avec lui, de la culture républicaine dans la sphère publique dans le cadre des fêtes, cérémonies et spectacles. Révélateurs de la sensibilité romantique de Tone, ses observations émues gênent un peu les historiens car elles paraissent trop éloignées de leur focale sur l'idéologie soi-disante " politique ».

Dès son arrivée à Paris, Tone fait la découverte enthousiaste d'officiers se promenant aux Tuileries :

De superbes figures, pas tant par leurs habits que par leur air, leurs manières et leur démarche. Je perçois maintenant la portée de l'expression une "nation en armes" (an armed nation) et je pense connaitre un autre pays tout aussi capable de produire autant de fiers gaillards. [...] Il serait absolument nécessaire d'adopter des mesures similaires à celles qui ont élevé et chéri cet esprit [en France], si jamais il plaît à Dieu Tout-puissant dans sa bonté de nous permettre de briser nos chaînes. 
Nous devinons qu'il ciblait spécifiquement un esprit patriotique et national dont le soldat était emblématique : « je pense que l'Irlande serait redoutable comme "nation en armes" ", répétant deux fois la formule en quelques lignes ${ }^{59}$.

En fréquentant le soir les spectacles parisiens, il découvre ce nouvel espace de sensibilisation patriotique. Il consacre ainsi une cinquantaine de lignes de son journal à une description exaltante du ballet l'offrande à la liberté, célèbre tableau patriotique de Gossec avec arrangement sur la Marseillaise, auquel il assiste à l'opéra ${ }^{60}$. La puissance d'évocation des cadences militaires et de la chorégraphie l'exalte, et il saisit sur le vif son expérience avec un ton à la fois naïf et émerveillé. Au centre de la scène se dresse une statue de la Liberté avec un autel flamboyant à ses pieds. Le public reçoit «avec transport " l'air civique Veillons au salut de l'Empire, et chaque fois que le mot "esclavage " (en français et en italiques dans son journal) est prononcé l'effet est comme un «choc électrique ». Puis, on chante l'hymne des Marseillais ce qui rehausse encore l'enthousiasme. Le refrain énergique «Aux armes Citoyens» est un signal aux acteurs qui dégainent leurs épées, tandis que les femmes se tournent vers eux, en approbation. Les enfants posent des paniers de fleurs aux pieds de l'autel de la déesse Liberté, et les actrices chantent "Liberté Liberté chérie ». Il avoue être profondément ému. La reprise de l'action, suite à l'offrande, rend "le spectacle véritablement digne d'une république libre » au cours duquel hommes, femmes et enfants se fondent, symbolisant la nation entière. La musique reprend subitement un air martial et les acteurs se lancent sur la scène, des gardes nationaux se précipitent avec leurs baïonnettes fixées, brandissant leurs sabres, et on agite le tricolore. Tone est bouleversé par la participation de véritables soldats et note bien le prix raisonnable des places permettant à tous d'y accéder. Il assiste aussi à une représentation du Serment de la Liberté à l'opéra et fait un éloge détaillé de ce spectacle républicain pour lequel on avait reconstitué sur la scène le Champ de Mars le jour de la Fête de la Fédération. Il est transporté par la participation des citoyennes aux évolutions militaires en rangées parallèles aux hommes, brandissant des sabres qu'elles leur présentent dans une mise en scène élaborée permettant aux deux sexes d'affirmer leur patriotisme ${ }^{61}$.

Désormais père de deux fils, pour lesquels il tient en partie son journal, il note (sans retenue) l'émotion profonde que lui inspire une fête municipale de la jeunesse à laquelle il assiste dans la ci-devant église Saint-Roch. L'intérieur est pavoisé aux couleurs nationales et parsemé de flambeaux illuminant un autel et une statue de la liberté. Les jeunes gens du district âgés de seize ans se présentent devant la municipalité pour recevoir leurs armes, et ceux de vint-et-un ans pour être inscrits comme citoyens et électeurs, en présence de leurs parents et de leurs amis. Suite à une procession militaire et à leur enrôlement, un officier prononce un discours sur leur devoir à la patrie et l'honneur de porter des armes pour sa défense. Mais ce sont les spectateurs, parents, amis et compagnes qui leur distribuent les sabres et leurs fusils: il avoue être emporté par l'enthousiasme, et «ne s'étonne plus des miracles que l'armée française a arraché sur le chemin de la liberté. [...] Les pauvres Irlandais sont un peuple brave, et [...] il ne serait pas impossible d'émuler parmi eux l'enthousiasme des Français. » Ébloui, il se dit « de plus en plus convaincu des effets puissants de ces spectacles publics, dirigés correctement, sur le cours d'une révolution ${ }^{62}$.» Ces passages font ressortir sa sensibilité exacerbée et son engouement pour le faste martial, mais Tone ne développe pas ses réactions émotives au point qu'il soit possible d'extrapoler sur la laïcisation de l'espace public, la religion civique, ou l'éducation patriotique ${ }^{63}$. Néanmoins, on le voit particulièrement sensible à la 
participation des différentes générations lors de ces cérémonies, et très ému par le rôle attribué aux personnages féminins dans la mise en scène et notamment leur reconnaissance et leur approbation de la bravoure masculine. Sans le dire explicitement, on peut se permettre de spéculer qu'il espérait aussi voir un jour ses propres enfants participer à de semblables rituels civiques élevant l'esprit de l'individu une fois la république d'Irlande établie.

31 Étranger privilégié, avant même de recevoir son brevet d'officier il est invité à la grandiose fête de la reconnaissance et des victoires célébrée au Champ de Mars, et même placé « au pied de l'autel. » A présent en France depuis plus de trois mois, il est beaucoup moins naïf et sait que le gouvernement oblige la population à assister aux chants civiques dans les salles de spectacles, le résultat étant souvent un public très flegmatique. Cela ne l'empêche pas de trouver le spectacle du jour et les chants d'hymnes civiques superbes, et d'admirer la distribution d'étendards et de guirlandes de chêne, emblème de la victoire, au plus beau grenadier de chaque corps d'armée. «J'étais particulièrement ravi de cette démonstration, et les larmes coulaient sur mes joues lorsque Carnot présenta aux soldats les couronnes et drapeaux ", récompenses si symboliques. Reprenant sa formule, il répète que «ce spectacle était digne d'une grande république." Il termine par "Vive la

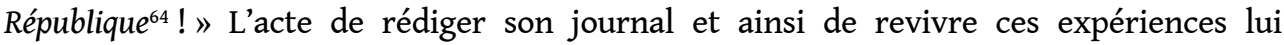
permettait de renforcer sa détermination.

Tone est dans ce sens en voyage d'initiation politique et en apprentissage de l'ailleurs : en arrivant en France « il découvre un pays républicain » et comme le souligne Pierre Serna, «dans sa fascination de cette république victorieuse et martiale qu'est le Directoire, il fonde l'espoir de la transporter en Irlande.» Depuis son exil en Amérique, il prend l'initiative de devenir voyageur volontaire au seul pays capable de répondre à son projet. Sa spécificité en tant que voyageur républicain existe. Par les pratiques culturelles politisées qu'il découvre en France, plus tard diffusées parmi ses proches par le biais de leur lecture éventuelle du journal, il observe et découvre un modèle de nation, à reconstruire en Irlande. Certes, il idéalise au départ sa terre d'asile, mais il y observe aussi que les citoyens y participent aux fêtes, cérémonies et spectacles et ne sont plus des serviteurs passifs d'une monarchie héréditaire. Même s'il ne le dit pas explicitement, comment en assistant à ces cérémonies et ces rituels civiques, ne pourrait-il pas imaginer les réimporter dans sa patrie, rehaussant la dignité de ses concitoyens ? À plusieurs reprises, surtout lors des premiers mois à Paris, il construit dans son imaginaire le modèle d'une " république autour d'un projet de citoyenneté méritocratique ${ }^{65}$.»

Cette admiration et cette adhésion au modèle de la république directoriale de la part de Tone démontre avant tout son pragmatisme, ayant trouvé un asile en France pour lui mais aussi pour sa famille qu'il fait venir. Seule la France peut mettre en œuvre son objectif ultime, arracher l'Irlande du joug anglais, mais il semble avoir rejeté le modèle américain qui l'avait particulièrement déçu. Il avait en effet publié en 1792 dans le Northern Star, journal des Irlandais Unis, une analyse favorable de la Constitution américaine puisqu'elle empêchait la corruption politique qu'il fustigeait en Irlande ${ }^{66}$. Pourtant, une fois aux États-Unis, Tone rejette violemment et les mœurs et le système politique de cette « république ». Dans une longue lettre à son ami et confident Thomas Russell, il écrit ainsi que «l'esprit du commerce a dévoré tout autre sentiment, et la vanité de la richesse mercantile n'est, je t'assure, que très légèrement inférieure aux prétentions hautaines de ton aristocratie.» A ce propos, Tone, fréquentant - avec discrétion - les milieux républicains démocrates de la diaspora irlandaise de Philadelphie, 
et à l'aune de son expérience irlandaise, analyse en effet la signature du traité de Jay avec l'Angleterre comme une lutte entre l'aristocratie et la démocratie :

Vois à présent comment l'Aristocratie s'est, quoi qu'il arrive, reconstituée! Je suppose que tout ce qui était possible de faire l'a été pour la neutraliser dans la Constitution de l'Amérique, mais en vain, elle continue encore son activité odieuse. Que m'importe qu'il s'agisse d'une aristocratie de marchands ou de pairs, élective ou héréditaire ? Cela reste toujours une aristocratie, incompatible avec l'existence d'une véritable liberté. Voilà à présent l'intérêt général de l'Amérique, sauf en ce qui concerne ceux de mes seigneurs les marchands, sacrifié, sa morale ternie, son amie [la France] à qui elle doit son existence, abandonnée au moment de la nécessité extrême, pour gratifier son ancien tyran [l'Angleterre]... et pourquoi ? pour amener plus de dollars dans les coffres de la pairie mercantile de l'Amérique. Je vois à présent plus clairement que jamais ou, plus exactement, la théorie est à présent démontrée par les faits : la liberté doit détruire l'aristocratie sous toutes ses formes possibles ou renoncer à son existence ${ }^{67}$.

34 Certes, une fois à Paris, il ne fait aucun commentaire sur les grandes institutions politiques de la République française, ne projetant pas explicitement leur adaptation dans une Irlande souveraine. Parmi ses nombreuses flâneries, il assiste une fois seulement à une séance du Conseil des Cinq Cents, la « Chambre des Communes française. » Il note les habits modestes des conseillers, leur air ordinaire, et leur manque d'ordre, qui lui rappellent un peu les réunions du Comité général des Catholiques d'Irlande, qui, en comparaison, se comportaient au bout du compte davantage en " gentlemen ». Qu'importe, les Français « avaient rendu humble toute l'Europe ${ }^{68}$ ». Peu de temps après son arrivée, il s'achète un exemplaire de la Constitution (de l'an III) chez Louvet au Palais Royal, mais ne fait aucune remarque sur le contenu de cet outil fondamental de la démocratie dont se passe bien le roi Georges, ou sur le républicanisme classique qui l'inspire ${ }^{69}$; il s'épanche plutôt sur les charmes de Lodoïska, épouse du libraire qui lui avait remis son achat. Marianne Elliott a su manier avec précaution les méandres émotifs de son journal, son style nerveux, rapide et l'autodérision dont fait preuve Tone. Ce faisant néanmoins, elle se distance un peu trop de cette source mercuriale qui saisit ses émotions sur le vif; le journal est en fait très peu cité dans la biographie. Elle se dit frappée par le peu de fréquence de «mentions de concepts autour de la nation [...] qu'on associe si souvent à son nom $^{70}$. " Il est probable que les excès de sentimentalisme de Tone engendrés par les fêtes et les spectacles patriotiques ont pu être négligés dans une approche très, même trop, axée sur la politique dans le sens traditionnel, car comment ne pas voir dans ces épisodes une appréciation fortement inspirante des rites symboliques d'une nation?

Dès lors, le manque d'originalité de la pensée républicaine de Tone est moins une faiblesse idéologique de sa part qu'une reconfiguration opérée lors de son voyage en France, où il peut projeter son idéal républicain sur le pays qu'il découvre. Jusque récemment, en Irlande, le terme « républicain » était fort ambigu et pouvait évoquer une affiliation à des groupuscules souvent en dehors de la légalité. Certes, l'association immédiate entre "Wolfe» Tone et ce républicanisme souvent anti-démocratique avait été sensiblement amoindrie par la biographie méticuleuse de Marianne Elliott. Mais de beaucoup d'écrits des années 1980 ressort un certain défaitisme, en réaction à l'exaltation du héros, qui cherche à diminuer l'importance de la capacité d'agir de Tone, indéniablement son legs le plus décisif. De nos jours, remettre en question les antécédents de sa vision séparatiste et républicaine, et n'y voir qu'un accident de l'histoire déclenché par les évènements et son exil en Amérique, nous semble des arguments dépassés, ce qu'avait déjà souligné Thomas Bartlett ${ }^{71}$. 
La trajectoire de Tone est certes semée de paradoxes. Un épisode les condense tous : peu de temps après son arrivée à Paris, il avait visité le Panthéon avec Aristide Aubert Du Petit Thouars, aristocrate avec qui il avait noué une amitié lors de la traversée transatlantique. Le soir dans son journal, Tone note que c'est dommage que cet aventurier convivial soit un noble, ordre social qu'il méprise et déteste. Ayant admiré au cours de sa visite les cénotaphes des grands hommes de l'ère de la liberté française, il n'avait pas dévoilé à son guide l'émotion vive que suscitait en lui, fervent républicain débarquant en France, ce témoignage monumental d'une patrie reconnaissante. «Certes on ne peut rien imaginer de plus propice à inspirer l'esprit d'une grande nation qu'un édifice de ce genre, sacré à tout ce qu'il y a de sublime et d'illustre et de patriotique ${ }^{72}$.» Ainsi, malgré la référence implicite à la guerre d'indépendance américaine, les lacunes dans les sources correspondant à son court séjour américain (dont il ne reste que quelques rares lettres) rendent difficiles de savoir comment son républicanisme révolutionnaire s'est développé. Néanmoins, le contraste entre son rejet du modèle républicain américain et de ses mœurs et son adhésion au modèle français et directorial est frappant à la lecture de sa correspondance de 1795 , et surtout de son journal dès le début de sa mission française. Certes il idéalise le républicanisme français qu'il transporta en esprit vers l'Irlande, mais qui imprègne aussi les proclamations qu'il adresse à différents segments du "public » irlandais : notables, paysans, marins. Seule la future convention nationale irlandaise se prononcerait sur la forme effective du gouvernement, mais il est aisé de constater que le républicanisme, et notamment dans son incarnation française, demeure la référence constante et explicite de Tone. Exilé et voyageur parcourant l'Atlantique républicain entre Irlande, Amérique et France, Tone a ainsi achevé de construire son républicanisme dans un jeu de miroirs, de rejet et d'adhésion, en articulant les contextes politiques de ces trois pays ${ }^{73}$.

Ce premier républicanisme irlandais a été l'objet, après 1798, de multiples réinterprétations à travers le culte mémoriel de Tone, érigé en pilier de l'éducation patriotique des futures générations par Thomas Davis, la plus importante figure de la Jeune Irlande (Young Ireland), mouvement romantique nationaliste des années 1840. Davis perpétua et diffusa l'héritage de Tone, mais mourut en 1845, sans avoir pu accomplir sa mission: publier une première biographie du grand martyr de la liberté. Eduquant le peuple sur son passé en publiant des " analyses politiques, poèmes et récits historiques » inédits dans leur hebdomadaire, The Nation, les Jeunes Irlandais construisirent une véritable culture idéologique nationale par un "héroïque amour de [leur] pays ${ }^{74}$.» La fascination que le personnage de Tone et son appel réussi à la France exercèrent sur Davis reposa pleinement sur l'influence indiscutable de la Révolution française et de ses valeurs idéologiques, même si en réalité la France n'offrira plus jamais d'aide militaire ou de soutien aux insurgés en Irlande. L'obligation de se lancer seuls fut en fait leur force.

Fortement inspiré par les courants européens pour qui la connaissance du passé est la source d'un véritable caractère national, Davis déplorait l'absence d'un véritable mouvement artistique national, en dépit du nombre infini de sujets qu'offrait l'histoire de l'Irlande dans les sources écrites. L'agitation politique de Tone, la fondation des Irlandais Unis, et la promesse de faire appel à la France qu'il leur fait avant son exil figurent dans la liste des hauts faits qui ponctuent le "roman national » irlandais, débutant dans la préhistoire et se clôturant symboliquement avec l'acte de hisser le drapeau irlandais par une flotte et une armée irlandaises. Mais marqué par la lecture exaltante du journal de Tone, témoin intime de chaque étape de ses négociations et de sa formulation tenace de la 
souveraineté irlandaise dans les salons et couloirs du Luxembourg et des ministères français, Davis définit "Tone et Carnot $^{75}$ " comme un sujet national à dépeindre. Adolescent pendant la guerre d'indépendance en Amérique, et électrifié par les défilés et agitations des Volontaires à Dublin, entre 1779 et 1784 - une période fondamentale dans l'éveil du sentiment national irlandais pendant laquelle Hibernia, allégorie féminine de l'Irlande, allait supplanter pour les patriotes les symboles monarchiques - Tone fut luimême pleinement conscient de vivre une époque de transformations fondamentales, l'ère de la régénération de l'homme qu'incarne la République française, pendant laquelle l'individu peut façonner l'histoire. Sa mission en France devint ainsi emblématique de l'art du possible, et son énonciation de la souveraineté nationale dans un cadre républicain par divers moyens au cours de 1796 constitua un moment déterminant dans l'histoire de la République d'Irlande. Dès lors, l'oubli de Tone et de 1798 dans la mémoire de 1916 telle qu'elle s'est déployée en 2016, sans doute la conséquence de «l'hypermnésie » de 1798 lors du bicentenaire, n'en reste pas moins regrettable au moment où l'Irlande toute entière a réinterrogé ce que signifiait la promesse républicaine ${ }^{76}$ de la Proclamation de la «Irish Republic» de $1916{ }^{77}$.

\section{NOTES}

1. 1830 inspire fortement les Irlandais qui émulent Français et Belges en adoptant le concept des trois couleurs ; leur premier tricolore est fabriqué à Paris en 1848.

2. Ronan McGreevy, «Rising from the Ashes: 'Irish Republic' Flag on Display », Irish Times, 15 mars 2016. URL : http://www.irishtimes.com/news/ireland/irish-news/rising-from-theashes-irish-republic-flag-on-display-1.2573071.

3. Voir l'œuvre magistrale de Marianne ELLIOTT, Partners in Revolution The United Irishmen and France, New Haven and London, Yale University Press, 1982; Sylvie KLEINMAN, «Libérer ou exploiter ? L'Irlande dans la stratégie diplomatique et militaire de la France (1792-1805) », dans Frédéric Dessberg, Éric Schnakenbourg (dir.), Les Horizons de la politique extérieur française Stratégie diplomatique et militaire dans les régions périphériques et les espaces seconds (XVI ${ }^{\mathrm{e}}-\mathrm{XX}^{\mathrm{e}}$ siècles), Bruxelles, Peter Lang, 2011 p. 283-296.

4. Entrée du journal de Tone, 23 juin 1796: Theodore Moody, Robert MCDOWELL, Christopher woods (dir.), The Writings of Theobald Wolfe Tone, 3 vol., Oxford, Clarendon Press, 1998, 2001 et 2007 (ci-après: The Writings of Theobald Wolfe Tone), vol. II, p. 210. (Toutes les traductions proposées ici sont les nôtres.)

5. L'histoire des liens entre les Irlandais Unis et la France a été faite par Marianne eLLIOTT, Partners in Revolution: The United Irishmen and France, New Haven \& London, Yale University Press, 1982. Pour les premiers contacts d'Irlandais avec la France voir Mathieu FERRADOU, « Histoire d'un «festin patriotique» à l'hôtel White (18 novembre 1792): les Irlandais patriotes à Paris, 1789-1795 ", Annales historiques de la Révolution française (ci-après AHRF), n³82, octobre-décembre 2015, p. 123-143.

6. SHD (Vincennes), Armée : Registre de Côtes de l'Océan B5*-97, fo 78v, lettre 218, 5 messidor an IV (23 juin 1796) et suivante.

7. Joseph sтоск, Proceedings at Killalla during the French Invasion, Bath, Cruttwell, 1799, p. 5. 
8. Earl of Cavan to Edward Cooke, 7 November 1798, National Archives of Ireland, Rebellion Papers, 620/41/23, cité dans Theodore MOODY, Robert MCDowell, Christopher woods (dir.), The Writings of Theobald Wolfe Tone, vol. III, op. cit., p. 367-368.

9. Jean-Clément MARTIN, La Machine à fantasmes. Relire l'histoire de la Révolution française, Paris, Vendémiaire, 2012, incite à effectuer cette lecture à rebours afin d'accepter ces lectures fantasmées pour mieux les déconstruire.

10. William Theobald Wolfe TONE (dir.), Life of Tone, Washington, Gale \& Seaton, 1826. Pour le culte de sa mémoire, voir la trop courte conclusion dans Marianne ELLIOTT, Wolfe Tone, Liverpool, Liverpool University Press, 2012, p. 395-401; cette section clef de la biographie n'est pas remise à jour pour cette $2^{\mathrm{e}}$ édition, et ne situe pas l'hagiographie autour de Tone dans la très riche littérature interdisciplinaire sur les lieux de mémoire.

11. "Wolfe » est le nom d'un parrain et non son patronyme; on ne l'appellera Wolfe Tone qu'après sa mort, cette appellation s'insère donc dans la mémoire posthume.

12. Guy BEINER, Remembering the Year of the French. Irish Folk History and Social Memory, Madison, The University of Wisconsin Press, 2007.

13. Sylvie KLEINMAN, «Tone and the French Expeditions to Ireland 1796-1798: Total War, or Liberation? ", dans Pierre Serna, Antonino De Francesco, Judith A. Miller, (dir.), Republics at War, 1776-1840: Revolutions, Conflicts, and Geopolitics in Europe and the Atlantic World, Basingstoke \& New York, Palgrave Macmillan, 2013, p. 83-103.

14. Patrick Pearse, oraison sur la tombe de Tone, 22 juin 1913, cité dans The Coming Revolution. The Political Writings and Speeches of Patrick Pearse, Cork, Mercier, 2012, p. 51-53.

15. Maurice GoLDRING, Irlande. Idéologie d'une révolution nationale, Paris, Éditions sociales, 1975, p. 9 ; pourtant, Goldring ne le cite pas.

16. Marianne ELLIOTT, Wolfe Tone Prophet of Irish independence, Yale, Yale University Press, 1989.

17. Pour un résumé de sa carrière militaire, voir Sylvie Kleinman, « Un brave de plus. La carrière militaire de Theobald Wolfe Tone, héros du nationalisme irlandais et officier français, 1796-1798 ", Revue historique des armées [En ligne], n²53, 2008. URL : http://rha.revues.org/4602.

18. Marianne ELLIOTT, Wolfe Tone, $2^{\text {nde }}$ éd., op. cit., p. 139.

19. L'échec des expéditions explique sans doute le manque d'intérêt longtemps manifesté par les historiens français pour cet horizon de la politique étrangère directoriale ; pourtant, ce n'est pas un chapitre négligeable de l'histoire du régime à cette époque charnière de la guerre et des républiques sœurs. Voir Virginie MARTIN, La diplomatie en Révolution. Structures, agents, pratiques et renseignements diplomatiques. L'exemple des diplomates français en Italie (1789-1796), Thèse soutenue sous la direction de Jean-Clément Martin à l'Université Paris 1 Panthéon-Sorbonne, 3 vol., 2011.

20. Theodore MOODY, Robert MCDOWELL, Christopher woods (dir.), The Writings of Theobald Wolfe Tone, vol. II, op. cit., Tone à Pierre Auguste Adet, 10 août 1795, p. 3-7.

21. Ibid., p. 4.

22. Mémoire de Tone sur l'état de l'Irlande, traduit par Adet, Ibid., p. 7-10 (p. 9).

23. Ibid., p. 7.

24. Ibid., p. 64.

25. Delacroix au Directoire exécutif, 27 janvier 1796, Ibid., p. 39.

26. « Deuxième mémoire sur l'état de l'Irlande », 29 février 1796, Ibid., p. 90-91.

27. William Robert FitzGerald, deuxième Duc de Leinster, Whig, en faveur de l'émancipation catholique, et frère aîné de l'Irlandais Uni Edward FitzGerald, qui joue un rôle de stratège dans les préparatifs de l'insurrection en 1798.

28. Theodore MOODY, Robert MCDOWELL, Christopher woods (dir.), The Writings of Theobald Wolfe Tone, vol. II, op. cit., p. 111 (nous soulignons).

29. Michel vovelle, Les Républiques-sœurs sous le regard de la Grande Nation, 1795-1803, Paris, L'Harmattan, 2000, p. 87. 
30. Annie Jourdan, «La Révolution batave: un cas particulier dans la grande famille des républiques sœurs? », AHRF, n³78, 2014, p. 73-96 (et plus précisément p. 94-96). Voir également : Anna Maria RAO, "L'expérience révolutionnaire italienne", AHRF, n³13, 1998, p. 387-407. Pourtant, l'Irlande présente à son tour un cas particulier en ce sens : alors que la révolution n'y a pas eu lieu, la structure de sa société, sans toutefois reprendre le chiffre des sept huitièmes avancé par Tone, laissait entendre que la grande majorité du peuple irlandais aurait favorablement accueilli une invasion française, que ce soient les paysans catholiques s'ils avaient reçu la garantie de la liberté de culte et donc la suppression des dimes payées au clergé anglican, les marchands catholiques et les presbytériens du Nord privés de droits politiques complets face à une «Ascendancy » anglo-irlandaise ultra-minoritaire, tenant son pouvoir sur l'île grâce à son lien avec l'Angleterre.

31. Entrée du 18 juillet 1796, Ibid., p. 244 (nous soulignons).

32. Entrée du 21 mars 1796, Ibid., p. 120-121.

33. Pierre SERNA, "War and Republic: Dangerous Liaisons", dans Pierre Serna, Antonino De Francesco \& Judith A. Miller (dir.), Republics at War, 1776-1840 Revolutions, Conflicts and Geopolitics in Europe and the Atlantic World, Basingstoke, Palgrave Macmillan, 2013, p. 15.

34. Entrée du 22 février 1796, Ibid., p. 71.

35. Entrée du 11 mars 1796, Ibid., p. 107.

36. Ultán GILLEN, Le Directoire et le républicanisme irlandais, dans Pierre Serna (dir.) Les Républiques sœurs Le Directoire et la Révolution atlantique, Rennes, PUR, 2009, p. 332.

37. Entrée du 11 mai 1796 dans Theodore MOODY, Robert MCDOWELL, Christopher woods (dir.), The Writings of Theobald Wolfe Tone, Vol. II, p. 179.

38. Entrée du 10 février 1798 dans Theodore MOODY, Robert MCDOWELL, Christopher woods (dir.), The Writings of Theobald Wolfe Tone, vol. III, p. 202-203.

39. Tone à Clarke, 18 juillet 1796 dans Theodore MOODY, Robert MCDOWELL, Christopher woodS (dir.), The Writings of Theobald Wolfe Tone, vol. II, op. cit., p. 242. Pour cette raison, il est difficile de comparer l'expérience de Tone en tant qu'immigré à Paris avec celle des autres exilés patriotes, car il prend soin pendant toute la première phase de son séjour d'éviter tout contact en dehors des agents du gouvernement français qui pourrait le compromettre et attirer l'attention des espions anglais.

40. «Memorandum to General Clarke on the encouragement of chouannerie in Ireland, 4 April 1796 », AN, AF IV, carton 1671, f $65^{\mathrm{r}}-67^{\mathrm{v}}$; entrée du 2 avril 1796 dans Theodore MooDY, Robert MCDOWELL, Christopher woods (dir.), The Writings of Theobald Wolfe Tone, vol. II, p. 138. Voir également Sylvie KLEINMAN, «Initiating insurgencies abroad: French plans to chouannise Britain and Ireland 1793-1798 ", Small Wars \& Insurgencies Journal, vol. 25, n A August 2014, p. 784-799.

41. Annie JOURDAN, «La Révolution batave: un cas particulier dans la grande famille des républiques sœurs? ", AHRF, n³78, octobre-décembre 2014, p. 73-96 (p. 81).

42. Entrée du 22 janvier 1798 dans Theodore MOODY, Robert MCDOWELL, Christopher woods (dir.), The Writings of Theobald Wolfe Tone, vol. III, p. 193

43. Entrée du 27 avril 1797, Ibid., p. 70.

44. Marianne ELLIOTT, Wolfe Tone, op. cit., p. 352.

45. Entrée du $1^{\text {er }}$ juillet 1797 dans Theodore MOODY, Robert MCDOweLL, Christopher woods (dir.), The Writings of Theobald Wolfe Tone, vol. III, p. 98

46. On peut s'étonner de l'absence totale de ces documents produits dans le cadres des expéditions irlandaises dans Harry T. DICKINSON, Ireland in the Age of Revolution, 1760-1805, volume 4 (1791-1797) \& volume 5 (1798-1800), London \& Vermont, Pickering \& Chatto, 2013.

47. Imprimé à Brest par le Directoire : AN III $186^{\mathrm{B}}$, dossier 859.

48. Theodore MOODY, Robert MCDOWELL, Christopher woods (dir.), The Writings of Theobald Wolfe Tone, vol. II, op. cit., p. 375-392. 
49. Ibid., p. 376 et suivantes.

50. Stephen SMALL, Political thought in Ireland 1776-1798, Oxford, Clarendon Press, 2002, p. 250-253.

51. Theodore MOODY, Robert MCDOWELL, Christopher woods (dir.), The Writings of Theobald Wolfe Tone, vol. II, op. cit., p. 377.

52. Ibid, p. 386.

53. HIBERNICUS [Theobald Wolfe Tone], Spanish War! An enquiry how far Ireland is bound, of right, to embark in the impending contest on the side of Great Britain, Dublin, Byrne, 1790 (reproduit dans Theodore MOODY, Robert MCDOWELL, Christopher woods (dir.), The Writings of Theobald Wolfe Tone, vol. I, op. cit., p. 50-63.

54. "To the militia of Ireland", vers le 22 novembre 1796, dans Theodore MOODY, Robert MCDOWELL, Christopher woods (dir.), The Writings of Theobald Wolfe Tone, vol. II, op. cit., p. 392-396 ( p. 392).

55. Ibid, p. 393.

56. «To the Irishmen now serving aboard the British navy », vers le 22 novembre 1796, Ibid., p. 394-396 (p. 394).

57. Pierre RANGER, La France vue d'Irlande, op. cit., p. 20.

58. Edouard GUILLon, La France et l'Irlande pendant la Révolution, Hoche et Humbert: d'après les documents inédits des archives de France er d'Irlande, Paris, Armand Colin, 1888, p. 374.

59. Entrée du 16 février 1796 dans Theodore MOODY, Robert MCDOwELL, Christopher woods (dir.), The Writings of Theobald Wolfe Tone, vol. II, op. cit., p. 55 (l'emphase sur l'expression armed nation est dans le texte original).

60. François-Joseph GOSSEC, L'Offrande à la liberté, Paris, Imbault, 1792, $1^{\text {ére }}$ représentation : Paris, Opéra (Théâtre de la Porte Saint-Martin), le 30 septembre 1792.

61. Entrées des 13 et 14 février et du 13 mars 1796, Ibid., p. 49-52 et p. 108-109.

62. Entrée du 30 mars 1796, Ibid., p. 136.

63. Voir Mona Ozouf, La Fête révolutionnaire (1789-1799), Paris, Gallimard, 1988 ; Olivier IHL, La Fête révolutionnaire, Paris, Gallimard, 1996.

64. Entrée du 29 mai 1796, Ibid, p. 192 (l'expression finale est en français et l'emphase est la sienne).

65. Pierre SERNA, "Au bout du voyage, héritage d'une génération », et "La République est toujours un peu plus loin », dans Gilles Bertrand, Pierre Serna (dir.), La République en voyage, 1770-1830, Rennes, PUR., 2013, p. 333, et p. 403-413.

66. Marianne ELLIOTT, Wolfe Tone, $2^{\mathrm{e}}$ ed., op. cit., p. 257.

67. Tone à Thomas Russell, $1^{\mathrm{er}}$ septembre 1795 dans Theodore MOODY, Robert MCDOWELL, Christopher woods (dir.), The Writings of Theobald Wolfe Tone Vol. II, op. cit., p. 11-17.

68. Entrée du $1^{\mathrm{er}}$ avril 1796, Ibid., p. 139.

69. Voir Andrew JAINCHILL, "The Constitution of the Year III and the persistence of Classical Republicanism », French Historical Studies, vol. 6, n²3, summer 2003, p. 399-435.

70. Marianne ELLIOTT, Wolfe Tone, $2^{\text {nd }}$ ed., op. cit., p. 298.

71. Thomas Bartlett avait déjà remarqué la nécessité pour Tone de ne pas dévoiler ses véritables opinions en Irlande en dehors de lettres et conversations privées, ainsi que l'espoir de Tone qu'un environnement républicain mettrait fin aux aspects les plus rétrogrades du catholicisme dont il se méfiait: Thomas BARTLETT, "The Burden of the present: Theobald Wolfe Tone, Republican and Separatist ", dans David Dickson, Dáire Keogh, Kevin Whelan (dir.), The United Irishmen, Republicanism, Radicalism and rebellion, Dublin, Lilliput Press, 2003, p. 1-15.

72. Entrée du 7 février 1796 dans Theodore MOODY, Robert MCDOWELL, Christopher woods (dir.), The Writings of Theobald Wolfe Tone, vol. II, op. cit., p. 102.

73. Pierre SERNA (dir.), Républiques sœurs. Le Directoire et la Révolution atlantique, Rennes, PUR, 2009. 
74. Pierre RANGER, La France vue d'Irlande, op. cit., p. 51 et suivantes ; Marianne ELLIOTT, Wolfe Tone, $2^{\text {nd }}$ ed., op. cit., p. 397-399.

75. Thomas DAVIS, «Hints for Irish Historical Painting », dans David O’Donoghue (dir.), Essays, literary and historical. By Thomas Davis. Centenary edition, including several pieces never before collected, Dundalk, Dundalgan Press, 1914, p. 115.

76. Sur la réactualisation de ces engagements, voir Theo DORGAN, «To Rise Again, Revising the Republic ", dans Karin Fischer, Cliona Ní Ríordáin (dir.), L'Irlande et sa république, passée, présente et à venir/Ireland's Republic Past, Present and Future, Etudes irlandaises, ${ }^{\circ} 41,2$, automne-hiver 2016, p. $135-147$.

77. Nous tenons à remercier Mathieu Ferradou pour ses critiques constructives lors de la rédaction de cet article.

\section{RÉSUMÉS}

Theobald Wolfe Tone (1763-1798), révolutionnaire irlandais, officier français et premier grand martyr de la liberté de son pays, sera panthéonisé dans la mémoire irlandaise suite à la publication de ses écrits en 1826. Dans le journal qu'il rédige lors de sa mission clandestine en France, il devient le premier à énoncer le projet moderne de souveraineté irlandaise et d'une république démocratique. Reconnu comme le père fondateur du nationalisme irlandais, il sera l'objet d'un culte mémoriel dès le centenaire de la rébellion de 1798, et adulé par la génération de militants qui conduira l'insurrection de 1916 pour achever ce qu'il avait tenté d'accomplir. Tone est pourtant absent dans les débats et événements marquant le centenaire de 1916. Il est donc opportun de se pencher de nouveau sur la manière dont la première République française forme le cadre déterminant de cette phase charnière du nationalisme irlandais.

Theobald Wolfe Tone (1763-1798), Irish revolutionary, French officer, and Ireland's first true martyr of liberty, was 'pantheonised' after his writings were published in 1826 . The diary he kept during his clandestine mission to France allowed him to become the first to formulate a modern project for Irish sovereignty and a democratic republic. Recognised as the founding father of Irish nationalism, he was also the subject of a cult of memory around the time of the centenary of the 1798 rebellion, and then adulated by the generation of physical-force nationalists who launched the 1916 rising to complete what he had tried to achieve. Tone however remained absent in the debates and events marking the centenary of the rising. It is therefore timely to revisit the manner in which the first French republic was the defining framework of this first crucial phase of Irish nationalism.

\section{INDEX}

Mots-clés : Révolution, nationalisme, Irlande, souveraineté, république

Keywords : Revolution, nationalism, Ireland, sovereignty, Republic 


\section{AUTEUR}

\section{SYLVIE KLEINMAN}

Research associate

Centre for War Studies, Dept. of History,

Trinity College Dublin, 